\title{
Comparative study on the pathogenic effects of Diminazine aceturate sensitive and resistant isolates of Trypanosoma congolense in goats
}

\author{
Tesfaye Bekele ${ }^{1}$, Getachew Abebe ${ }^{2}$, Hagos Ashenafi ${ }^{3 *}$ and Yacob Hailu Tolossa ${ }^{3}$ \\ ${ }^{1}$ Oromia Pastoralist Areas Development Commission, P. O. Box120120, Addis Ababa, Ethiopia, \\ ${ }^{2}$ Food and Agriculture Organization of the United Nations, Addis Ababa, Ethiopia, \\ ${ }^{3}$ Addis Ababa University, School of Veterinary Medicine, Department of Pathology and Parasitol- \\ ogy, P. O. Box 34, Debre Zeit, Ethiopia.
}

*Corresponding author: E-mail: hagos83@yahoo.com

\begin{abstract}
The study was conducted in goats to compare the pathogenic effects of Trypanosome congolense known to be resistant and sensitive to Diminazine aceturate at $7 \mathrm{mg} / \mathrm{kg}$, respectively. Fifteen male goats, 6 to 10 months of age were randomly divided into three groups. The first group (Group A) was artificially infected via intravenous route with the Diminazine aceturate resistant $T$. congolense isolate while the second group (Group B) received Diminazine aceturate sensitive T. congolense isolate and the third group was left non- infected control (Group C). The goats were clinically monitored for 11 weeks and blood samples were collected three times a week for parasitological and hematological examinations. The mean body temperature was found to fluctuate between $\left(37.2^{\circ} \mathrm{C} \pm 0.24{ }^{\circ} \mathrm{C}\right.$ and $39.0{ }^{\circ} \mathrm{C} \pm 0.30{ }^{\circ} \mathrm{C} 37.5^{\circ} \mathrm{C} \pm 0.10{ }^{\circ} \mathrm{C}$ and $40.0^{\circ} \mathrm{C} \pm 0.48^{\circ} \mathrm{C}$ in groups $\mathrm{A}$ and $\mathrm{B}$, respectively with statistically significant $(p<0.05)$ differences. A mean parasitaemia score of $2.5 \pm 0.48$ and $4.0 \pm 0.0 .50$ was recorded in groups $A$ and $B$, respectively with significant variation $(p<0.05)$. The mean packed cell volume was also varied between $27.0 \% \pm 0.48 \%$ to $18.5 \% \pm 0.36 \%$ and $26.0 \% \pm 0.25 \%$ to $17.4 \% \pm 0.0 .47 \%$ in groups $\mathrm{A}$ and $\mathrm{B}$, respectively with statistically significant $(\mathrm{p}<0.05)$ difference. A marked decline in mean packed cell volume and raise in parasitaemia was noticeable in group B as compared to group A. The difference in packed cell volume among the groups was statistically significant $(p<0.05)$. In the control group, the mean body temperature and packed cell volume recorded was in the physiological range throughout the trial period. The present study disclosed that in spite of differences in the level of parasitaemia, anemia was found to be the prominent clinico-pathological finding in both Diminazine aceturate resistant and sensitive isolates of $T$. congolense infected goats.
\end{abstract}

Keyword: Anemia/Diminazine aceturate sensitive/Diminazine aceturate resistant, Parasitaemia, PCV, T. congolense.

http://dx.doi.org/10.4314/evj.v16i1.5 


\section{Introduction}

Trypanosomiasis is a protozoan disease caused by various species of Trypanosomes belonging to the genus Trypanosoma which are found in the blood and tissue of their host and generally transmitted by haematophagus arthropod vector (Jordan, 1986). .It is one of the most researched diseases in Africa and is known to be a major constraint to livestock production and their products on approximately 10 million $\mathrm{km}^{2}$ of land, covering 37 countries (FAO, 2000).

The most important species of Trypanosome affecting sheep and goat are Trypanosome congolense, Trypanosome vivax and Trypanosome brucei. Moreover, species such as Trypanosome simae can also affect sheep and goats (Putt et al., 1980, Radostitis et al., 2006). Trypanosomes show different degree of pathogenecity among the domestic animals which they parasitize. There are a number of trypanocidal drugs available for treating and preventing the disease in endemic areas. These drugs have been being used for over many years. Furthermore, as drugs are not always available, are expensive, problem of under dosing and use of some drugs for both prophylaxis and chemotherapy could lead to the occurrence of drug resistance (Sewell and Brocklesby, 1990).

There are observable differences in the pathogenecity between trypanocidal drug sensitive and resistant stocks of trypanosome as reported by different workers. More specifically, there was an observation that Trypanosoma congolense strains which had broken through prophylactic drugs appear in the blood in a very low number at an irregular interval, and were of mild pathogenecity (Hassen, 1996). However, these are limited information on the pathogenic effects of Trypanosoma congolense in small ruminants. Therefore, the major objective of the present study was to compare the pathogenic effects of Diminazine aceturate sensitive and resistant Trypanosoma congolense field isolates in goats under laboratory condition. 


\section{Materials and methods}

\section{Study description and animals}

This study was conducted at the Faculty of Veterinary Medicine, Debre Zeit on a total of fifteen male indigenous goat breed, 6-10 months of age, purchased from an area free of tsetse infestation. During the adaptation period of one month, hematological examinations were done to screen the goats for trypanosomosis and other haemoparasites. Besides, the packed cell volume was monitored during this period. The goats were all treated with Fenbendazole $(7.5 \mathrm{mg} / \mathrm{kg})$ against helminthosis, and sprayed with acaricide (CBM 8). The goats were ear tagged. They all were kept in one barn during the study period. During the day time, they were let to graze on the nearby field. Water supply was ad libitum.

\section{Study isolates}

The study was done with two Trypanosoma congolense isolate, which are identified to be sensitive and resistant to the therapeutic dose of Diminazine aceturate at $7 \mathrm{mg} / \mathrm{kg}$ body (Hassen, 1996), respectively.

\section{Experimental design and study protocol}

The goats were randomly divided into three groups (Table 1). The first two groups were artificially inoculated intravenously with Trypanosoma congolense isolates and the third group was left as control. Passages were done from donor mice previously infected intraperitonially with the trypanosome isolates. The mice were anaesthetized with chloroform and blood collected from the heart into heparinized syringe. The goats were inoculated with the mice blood with high parasitaemia ( $10^{4}-10^{5}$ trypanosomes $/ 0.5 \mathrm{ml}$ ) through the jugular vein. The goats were clinically monitored for twelve weeks. Accordingly, the mucous membrane was examined, the rectal temperature of the goats was recorded and blood samples were taken every morning three times a week for laboratory examination. 
Table 1. Experimental design and study protocol.

\begin{tabular}{lcl}
\hline Groups & No of goats & Description \\
\hline Group A & 5 & $\begin{array}{l}\text { Resistant to the therapeutic dose of Diminazine } \\
\text { aceturate at } 7 \mathrm{mg} / \mathrm{kg} \text { body }\end{array}$ \\
Group B & 5 & $\begin{array}{l}\text { Sensitive to the therapeutic dose of Diminazine } \\
\text { aceturate at } 7 \mathrm{mg} / \mathrm{kg} \text { body } \\
\text { Control }\end{array}$ \\
\hline
\end{tabular}

\section{Laboratory examination}

\section{Measurement of packed cell volume}

About $5 \mathrm{ml}$ blood was collected from the jugular vein directly into a heparinized tube and mixed gently. Following the packed cell volume measurement was done according to (Woo, 1970) and the value was expressed as a percentage.

\section{Estimation of parasitaemia}

Dark ground buffy coat examination were performed according to the technique indicated by (Murray et al., 1977) for the estimation of parasitaemia. Accordingly, blood was taken in a capillary tube and centrifuged at $1200 \mathrm{rpm}$ for 5 minutes. The tube was cut $1 \mathrm{~mm}$ below the buffy coat layer and $1 \mathrm{~cm}$ above the plasma layer, the content was expressed on the slide and covered with slip. The smear was examined under X40 objectives. 20 microscopic fields were examined for a smear and the level of parasitaemia was estimated according to Paris et al (1982).

\section{Data analysis}

Data such as temperature, packed cell volume and parasitaemia were stored in Microsoft Excel spreadsheet for each group. Data were analyzed using repeated measure analysis of variance in SPSS version 15.0 (2000). The $p$ value for the significant level was considered to be 0.05 .

\section{Results}

\section{Clinical examination}

Three course of the disease was observed during the study in both infected groups; acute, sub acute and chronic were observed in both infected groups. In group A, the goats showed acute and chronic courses of illness. The acute form was characterized by early onset of illness including lethargy, depression, fever, 
anemia within 2 weeks post infection. The chronically sick goats remained parasitaemic up to 11 week post infection.

In group B, a sub acute and chronic course of the disease was developed. The sub acute form of the infection lasted 4 to 8 weeks post infection. During this period there were signs of anemia, weakness and lethargy. In the chronic form, the goats survived with different levels of parasitaemia up to 11 weeks post infection.

\section{Temperature}

The mean rectal temperature has been fluctuating between $37.2^{\circ} \mathrm{C} \pm 0.24^{\circ} \mathrm{C}$ and $39.0^{\circ} \mathrm{C} \pm 0.30^{\circ} \mathrm{C}$ in group A while it has been fluctuating between $37.5^{\circ} \mathrm{C} \pm 0.10$ ${ }^{\circ} \mathrm{C}$ and $40.0^{\circ} \mathrm{C} \pm 0.48^{\circ} \mathrm{C}$ in group $\mathrm{B}$. The difference in mean rectal temperature between the groups was statistically significantly $(\mathrm{p}<0.05)$. In the control group, the mean rectal temperature was maintained within the range $37.0^{\circ} \mathrm{C} \pm 0.24{ }^{\circ} \mathrm{C}$ and $37.5{ }^{\circ} \mathrm{C} \pm 0.10{ }^{\circ} \mathrm{C}$ throughout the study period (Figure 1 ).

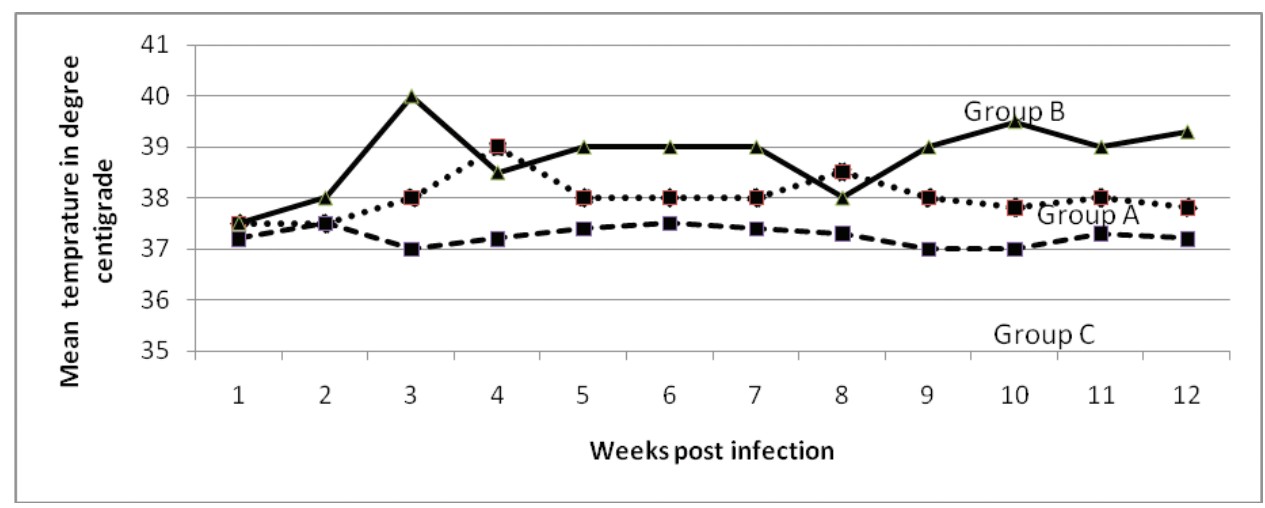

Figure 1. Mean weekly temperature of infected and control groups.

\section{Parasitaemia}

Initial parasitaemia was developed 15 days post infection and the first peak mean parasitaemia of $2.5 \pm 0.48$ occurred four weeks after infection in group A. The subsequent parasitaemic waves were lower than that initial peak parasitaemia score and the parasite populations were scanty, the average parasitaemia score was $1.28+$ during the periods following the initial peak parasitaemia. In group B, however, the parasitaemia developed within 6-9 days post infection. The first peak parasiteamia $4 \pm 0.50$ in DG score was discovered in the third week post infection. Following the first peak of parasitaemia, there 
were series of parasitaemia waves with lower scores, the average being $2.6+$ (Figure 2). This peak parasitaemia in group B was significantly higher $(p<0.05)$ than that of group A.

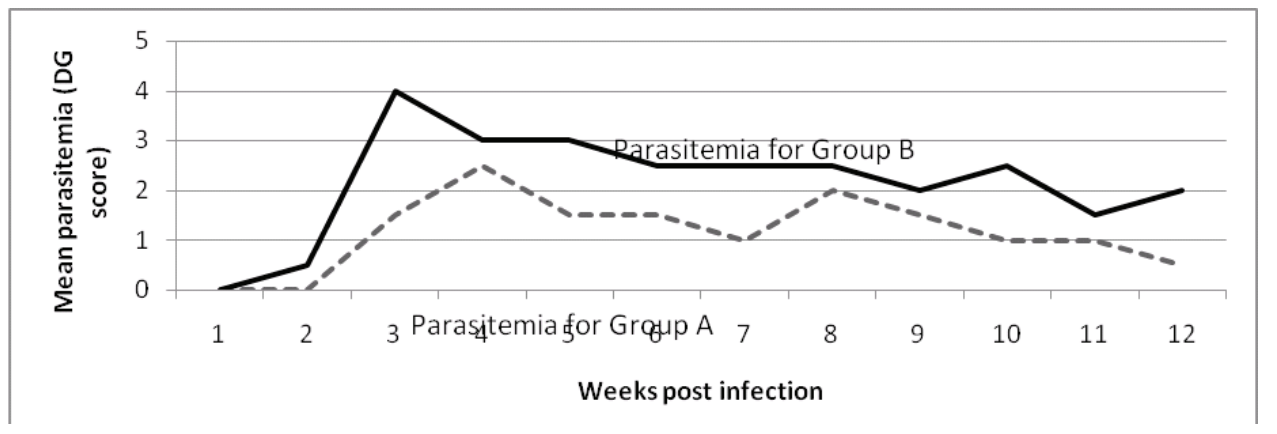

Figure 2. Mean weekly parasitaemia (DG score) of infected groups.

\section{Packed cell volume (pcv)}

In group $\mathrm{A}$, a decrease in mean packed cell volume from the mean initial packed cell volume of $27 \% \pm 0.48 \%$ to $24.9 \% \pm 0.41 \%$ was registered at the third week post infection. There was a significant decline $(p<0.05)$ in the packed cell volume to $18.5 \% \pm 0.36 \%$ at the fifth week post infection. In group B, there has been decline in mean packed cell volume to $22.2 \% \pm$ from the initial mean packed cell volume of $26 \% \pm 0.25 \%$ after two week post infection. Further decline up to $16.2 \% \pm 0.10 \%$ was recorded at week four (Figure 3 ). The decline in the packed cell volume was found to be significant $(p<0.05)$.

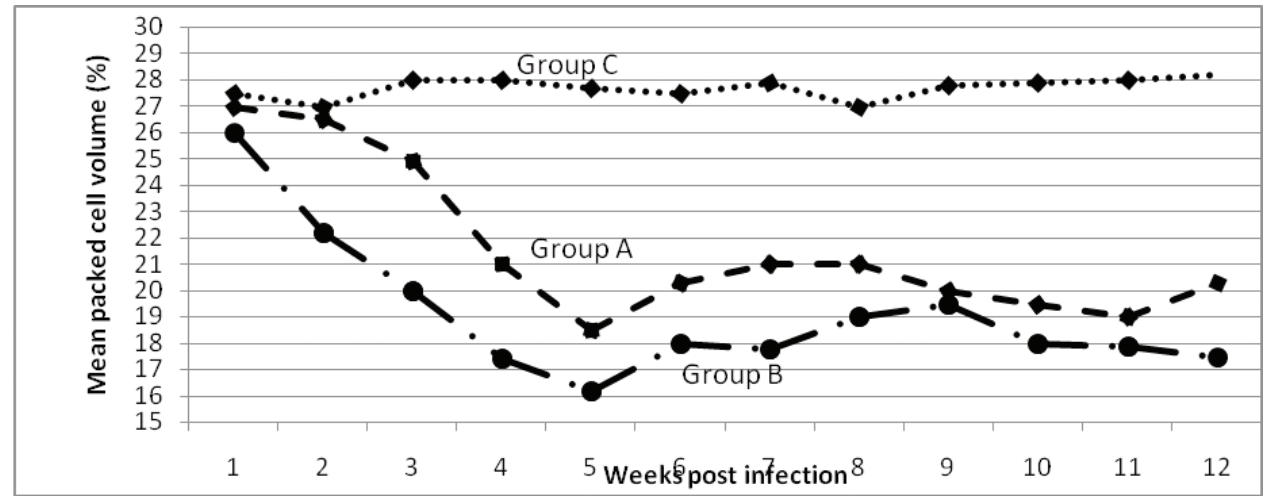

Figure 3. Mean weekly packed cell volume of infected and control groups. 


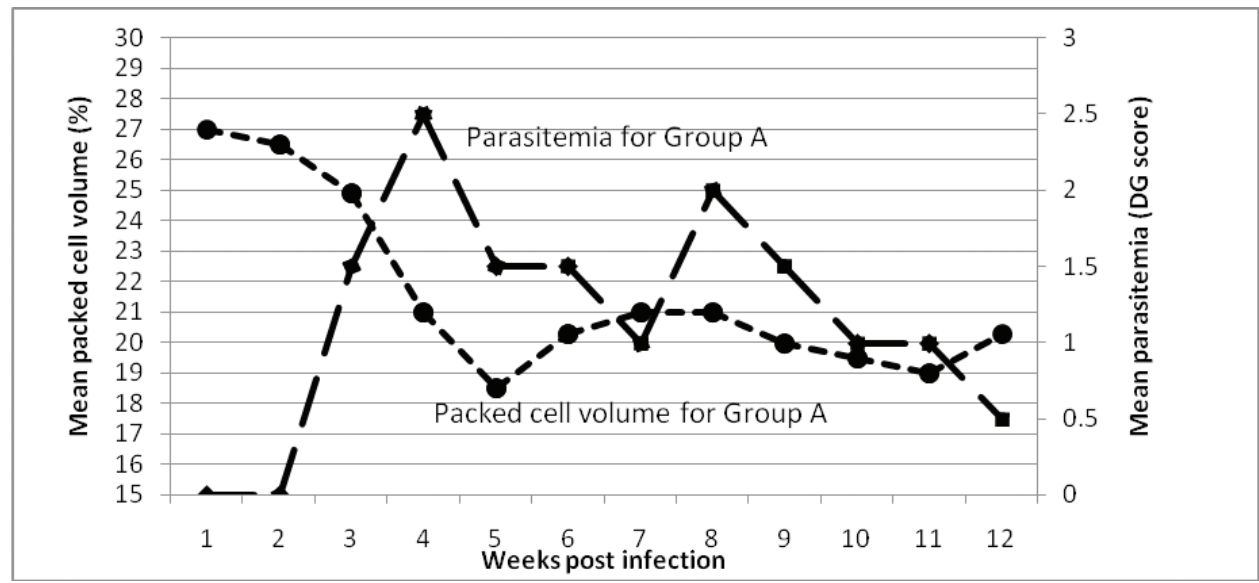

Figure 4. Mean weekly packed cell volume versus parasitaemia for groups A.

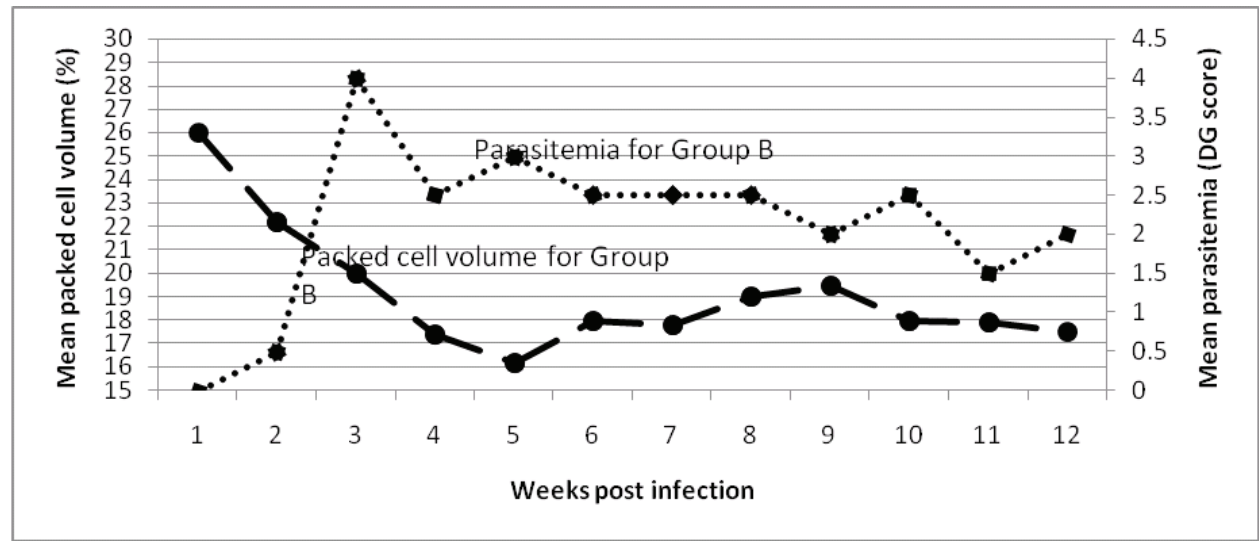

Figure 5. Mean weekly packed cell volume versus parasitaemia for groups B.

\section{Discussion}

Depending on such factors like the concentration of trypanosomes in an inocculum, the strain of the trypanosome and the nature of the host species, trypanosomiasis could have an acute episode lasting for few days and a chronic stages running for longer period of time which may be interrupted by periodic incidents of severe illness or could undergo a spontaneous recovery. In this study three types of clinical pictures were observed during the entire study period. These are acute form, sub acute form and chronic form. Accordingly, the clinical observation in this study showed that in group A, the infected sick goats could not resist the initial peak parasitaemia which was followed by a 
rapid decline in the mean haematocrit value at week five post infection. In the sub acute form, the goat survived the first peak parasitaemia but the infection persisted with occurrence of subsequent waves of parasitaemia. These waves of parasitaemia have led to the progressive decline in packed cell volume. As a result, the goats become weak, depressed, and severely anaemic as seen by the decline of the mean haematocrit of $16.2 \%$ at week 5 post infections, especially in group B.

As it is the case in most African trypanosomal infections, the initial systemic proliferation of the two isolates reach a peak and then declined. Remissions were short lived and the goats developed a fluctuating chronic parasitaemia up to the end of the study period. The survivors of the infection in both groups have eliminated most of the parasites in the initial parasitaemia, but some of the parasites manage to survive up to the end of the study period. Thus a chronic fluctuating parasitaemia developed in both group A and group B. Similar observations in small East African breed of goat known as the Imbo breed (Mutayoba et al., 1989).

The significantly elevated mean body temperature $(p<0.05)$ that was observed in group B could be attributed to the peak parasitaemia scores, although the extent of the rise in body temperature may or may not reflect the degree of parasitaemia. A similar significant elevation of body temperature at peak parasitaemia observed in group could be attributed to the level of parasitaemia. In all the infected goats, the body temperature fluctuated between $37.2^{\circ} \mathrm{C} \pm 0.24{ }^{\circ} \mathrm{C}-40.0^{\circ} \mathrm{C} \pm 0.48^{\circ} \mathrm{C}$. However, higher temperature peak were occasionally encountered in chronic cases which were not associated with rising parasitaemia. The higher mean body temperature in group B could be attributed to the higher mean parasitaemia levels in the group. The mean body temperature of the control goats in the entire study weeks were in the range of $37.0^{\circ} \mathrm{C} \pm 0.24^{\circ} \mathrm{C}$ and $37.5^{\circ} \mathrm{C} \pm 0.10^{\circ} \mathrm{C}$.

In group B, parasitaemia has developed in 6-9 days post infection. This finding is not in agreement with the findings of Burundi et al (1994) in which they found an average prepatent period of 3 days post infection for Diminazine aceturate sensitive stock of Trypanosoma congolense. The difference could be attributed to difference in the dose of the innoculum, the no of passages of the Trypanosome stocks, and the age of the goats. Although it is difficult to explain the exact cause and the mechanism underlying the higher parasitaemia scores registered in in group B during the subsequent weeks as compared to group A, it could be due to the difference in the multiplication 
rate of the isolates. The individual difference among the goats in response to the parasites multiplication could also be account for the difference in the level of parasitaemia. Similar observations were reported by Mamman et al (1995) who observed that Diminazine-resistant Trypanosoma congolense occur at low levels in trypanosome populations.

In group A, the goats became parasitemic within 11-13 days post infection. The finding is almost similar to that of Burundi et al. 1994, who reported a prepatent period of 14 days in Diminazine aceturate resistant Trypanosoma congolense stock in mice. The decline in the level of parasitaemia in both isolates especially from week 5 onwards can be attributed to the ability of the host to eliminate most of the population of the parasite following the initial peak parasitaemia.

Anemia is recognized as the most important clinical manifestation of naturally occurring and experimentally induced animal trypanosomiasis (Murry and Dexter, 1988). In this study, the artificially induced caprine trypanosomiasis resulted in the marked decline of the hematocrit value as compared to the control goats indicating that anemia is the major pathology as in large animals. There is lack of information regarding the events occurring between the time of inoculation and challenge and the appearance of the parasite in the circulation. Similar observation was reported by Stephen (1986).

The mean packed cell volume of group B was lower than of group B. This could be attributed to the series of highest parasitemic waves occurred during these weeks in the group. In both infected groups the mean packed cell volume has shown a slight improvement from week 5 onwards. This can be attributed to the tendency of the host to reduce the parasite load in the latter weeks of infection. Naturally, it is said that young animals are tolerant to trypanosome infection. Besides, the environmental stress was minimum which may contribute to the improvement in the mean packed cell volume. The control group has a mean packed cell volume ranging $27.0 \% \pm 0.20 \%$ to $28.2 \% \pm 0.17 \%$ through out the study period.

There was an assertion that drug resistant isolates cause mild anemia (Stephen, 1986). The result of the present study affirmed that there was a difference in the level of anemia between the two groups as evaluated by mean packed cell volume. Diminazine aceturate sensitive Trypanosoma congolense isolates have showed higher parasitaemia scores as compared to Diminazine aceturate resistant Trypanosoma congolense isolates. In conclusion, anemia as indicated 
by decline in packed cell volume was found to be the main pathology in both infected groups. All the animals had developed the disease and there was notable distinction in the clinical pictures of the disease between the groups. The present study has certain limitations which such as small sample size, it was a controlled experiment and the isolates were highly passaged in mice which might have reduced the pathogenecity of the parasites which could in turn affect their pathogenic effects. These points inquire further study with low passed isolates in larger sample animals, preferably under field condition.

\section{Refernces}

Burundi, E. M., Peregrine, AS., Mejia, P.O., Mbiuki,S. M. and Murphy, N. B., 1994. Response of Diminazine aceturate resistant and Diminazine aceturate susceptible Trypanosoma congolense to treatment with Diminazine when occurring together as a mixed infection. Annuals of tropical medicine and parasitology, volume 88 No 6 page 595-606.

FAO., 2000. A field guide for the diagnosis, treatment and prevention of African animal trypanosomosis, 2nd edition. FAO, Rome, Italy.

Hassen, C., 1996. Drug sensitivity trails on Trypanosome congolense filed isolate from southern Ethiopia. DVM thesis. Addis Ababa University, Faculty of veterinary medicine, Debra site Ethiopia.

Jorden, A.M. ,1986. Trypanosomiasis control and African Rural development. Longman Group Ltd. New York.

Mamman, M., Williams, DJ., Murphy, NB., Peregrine, AS., 1995. Apparent rarity of Diminazine-resistant trypanosomes in goats infected with a Diminazine-resistant population of Trypanosoma congolense. Res Vet Sci., 58 (2):113-8.

Murray, M and Dexter, T. M., 1988. Anemia in African Trypanosimiasis. A review. Acta Tropica 45: 389-432.

Murray, M., Murry, P. K. and Inlayer, I. M., 1977. An improved parasitological technique for the diagnosis of African trypanosomosis. Transcript of the royal society of Tropical medicine and hygiene 71: 325-326.

Mutayoba, B. M., Gombe, G., Wainde, E.N., Kaaya, G.P., 1989. Comparative trypanotolerance of small East African breed of goats from different localities to Trypanosoma congolense infection. Vet. Parasitol, 31: 95-105. 
Paris, J., Murry, M., and Kovatochi, R. M., 1979. Trypanosoma congolense. Calf erythrocyte survival. Exp. Parasitol, 48 pp 118-125.

Putt, S.N.H., Shaw, A.P.M., Mathewlan, R.W., Underwound, Mr. James, A. and Hallam, M.J. 1980. The social and economic application of Trypanosomosis control. A study of its impacts on livestock production and rural development in Northern Nigeria. Veterinary Epidemiology and research unit department of agriculture and horticulture. University of Reading, pp. 37-38.

Radostitis, O. M., Gay, C. C, Hinchliff, W.K. and Constable, D. P., 2006. Veterinary Medicine. A Text Book of the Disease of Cattle, Sheep, Pigs, Goats and Horses. $10^{\text {th }}$ Edition, W.B. Saunders Company Ltd. London: pp. 1140-1141.

Sewell, M.M.H. and Brocklesby, D.W., 1990. Hand book on animal disease in the tropics, Bailliere Tindall, London, pp.205-207.

SPSS., 2000. Statistical Package for Social Sciences. Version 11.3, SPSS Inc, 19892002, USA.

Stephen, E.. 1986. Trypanosomiasis: A veterinary prospective $1^{\text {st }}$ ed. Pp 44-49.

Woo, P.I.K., 1970. Microhematocrite centrifugation technique. Canadanian Journal of Zoology, 47: 921-923. 